\title{
Hydrodeoxygenation of acetone-furfural condensation adducts over alumina-supported noble metal catalysts
}

\author{
Laura Faba, Eva Díaz, Salvador Ordóñez ${ }^{1}$ \\ Department of Chemical and Environmental Engineering, Faculty of Chemistry, University of \\ Oviedo, JuliánClavería s/n, 33006 Oviedo, Spain
}

\begin{abstract}
The hydrodeoxygenation (HDO) of aldol condensation adducts is of key interest in the preparation of biofuels from biomass by catalytic routes. In this work, furfuryldeneacetoneis taken as model of biomass-derived condensation adduct with furanic rings, unsaturations and carbonyl functionalities. Four noble metal catalysts (alumina- supported $\mathrm{Ru}, \mathrm{Rh}, \mathrm{Pd}$ and $\mathrm{Pt}$ ) were tested. Obtained results show thatRh and Ru catalysts are only active for the hydrogenation of aliphatic double bonds; whereas Pd, and specially Pt catalysts, are active for the total HDO of the adduct, yielding n-octane, with selectivities higher than $30 \%$ at $493 \mathrm{~K}$ after $24 \mathrm{~h}$ on stream (total conversion and carbon balance closure higher than $90 \%$ ). Based on these results, a mechanism (considering serial, parallel and equilibrium steps) and the corresponding kinetic model have been proposed for explaining the different selectivity trends observed for these metals.
\end{abstract}

KEYWORDS: $2^{\text {nd }}$ generation biofuels;platform molecules; kinetic models; palladium;platinum;hydrogenation

\footnotetext{
${ }^{1}$ Corresponding autor. Tel.: +34 985103 437; Fax:+ 34985103434.

e-mail address: sordonez@uniovi.es (S. Ordóñez)
} 


\section{Introduction}

Biomass constitutes a promising raw material for renewable fuels and chemicals, especially for the manufacture of drop-inliquid fuels[1]. Aldol condensations of sugar-derived aldehydes are aqueous phase processes with significant advantages over thermo-chemical and biological methods[2]. These reactions use as raw materials a large amount of bio-based platform molecules, and can be performed at ambient conditions[3,4]. Hydrodeoxygenation (HDO) of the condensation adducts leads to drop-in fuels, (from C8 to C15 lineal alkanes, a diesel-quality fraction)[5,6]. Gasoline-range hydrocarbons can also be obtainedfrom alcohols, aldehydes or ketones, products of the fast pyrolysis of the lignocellulosic biomassthrough condensationhydrogenation sequences[7,8].

Hydrodeoxygenation of these condensation adducts to $n$-alkanes requires several steps to remove the oxygen atoms present in different functional groups $(\mathrm{C}=\mathrm{O}, \mathrm{C}-\mathrm{OH}, \mathrm{C}-\mathrm{O}-\mathrm{C})$ : hydrogenation of aliphatic instaurations $(\mathrm{C}=\mathrm{C})$, furan-ring hydrogenations, heterocyclic ring opening and dehydration/hydrogenation steps. The complexity of this reaction is largely increased due to the steric interactions of furan rings, which modify the general mechanism of individual reactions[9].

A limited number of works devoted the total HDO of these compounds have been published. Contrary, the hydrogenation of furanyl compounds to alcohols has been deeply studied in gas phase. High selectivities with $\mathrm{Co}$ and Ni-Fe catalysts at temperatures higher than $500 \mathrm{~K}$ have been reported, although with a strong catalytic deactivation[10,11]. Less deactivation was observed in liquid phase HDO over Ni supported catalysts[12,13], with selectivities higher than $98 \%$. Likewise, dehydration/hydrogenation processes to remove oxygenated groups were deeply studied for functionalized lineal hydrocarbons over noble metals (Pt group) and sulfide 
catalysts[14]. The sulfur leaching, as well as the formation of undesirable S-containing products, prevents the use of sulfide catalysts when using biomass- derived compounds[15]. In addition, the concentration of sulfur compounds is lower in the case of streams coming from biomass processes than in petrochemical processes. It should be also noted that in lignocellulose materials, sulfur is mainly associated to the lignin, and therefore is removed in the pretreatment of these materials. Consequently, noble metals seem to be the optimum catalysts for these reactions. Dehydration was also observed as side-reaction in the hydrogenation of furfural using $\mathrm{Cu} / \mathrm{SiO}_{2}$ at temperatures higher than $523 \mathrm{~K}[16]$ and in hydrogenations of polyalcohols in presence of $\mathrm{Pt}$ or $\mathrm{Ru}$ and acid sites[17]. In presence of $\mathrm{Pd}$, competition of this reaction with decarbonylation was observed[18].

Furmisky et al.reviewed the application ofHDOreactions to small aromatic compounds obtained from biomass, using oxides supported on alumina as catalysts[19]. More recent works dealing with the biomass derived fraction (instead of the oil-derived one) used Pt/based catalysts at 723 $\mathrm{K}$ and $5 \mathrm{MPa}[20]$, or $\mathrm{Pd} / \mathrm{based}$ catalysts working at supercritical conditions[21]. Different sideproducts and hydrogenated intermediates were detected, limiting the selectivity of corresponding alkanes. Likewise, it was observed that lower temperatures and pressures are desirable to prevent coking and side reactions, thus the convenience of carrying out the reaction in liquid phase is clear[22]. However, there is no agreement in the hydrodeoxygenation mechanism. Therefore, this process has been usually presented for sugar-derived aldehydes as two independent reactions: a first hydrogenation of condensated adducts removing the aliphatic $\mathrm{C}=\mathrm{C}$ insaturations (catalyzed by noble metals at moderate temperature and pressure)[23] and, a second step of four dehydration/hydrogenation $(4 \mathrm{ADP} / \mathrm{H})$ reactions at stronger conditions (using bifunctional catalyst with metal and acid sites) which produce the alkanes [20,24]. 
In this work, the total hydrodeoxygenation of condensated adducts in one step is studied. This reaction is the last step in the manufacture of diesel blends from cellulosic biomass (Scheme 1). The main scope of this work is to identify the most effective active phase, the optimum reaction conditions and to propose reaction pathways for the hydrodeoxygenation of condensated adducts. The study is focused on the furfuryldeneacetone (C8), the first condensation adduct obtained by aldolization of furfural and acetone[4]. Four different noble metals $(\mathrm{Ru}, \mathrm{Rh}, \mathrm{Pd}$ and $\mathrm{Pt})$ supported on alumina were tested at different temperatures. Group VI-VIII metals have been previously tested in hydrogenations at low-medium temperatures showing high catalytic activity, but also a high capacity of adsorption and activity for side reactions[25]. Pd and Rh are considered good catalysts for hydrogenation of aliphatic insaturations[26,27] whereas $\mathrm{Ru}$ and $\mathrm{Pt}$ show high activity in deoxygenation steps[28,29]. Alumina was chosen as support because of its acidity, which can favor some steps of the HDO reaction, but it considered mild enough for not promoting coke formation reactions.

\section{Experimental}

\subsection{Catalysts characterization}

Catalysts used in this work are BASF Escat series of $0.5 \%(\mathrm{w} / \mathrm{w})$ of $\mathrm{Pd}, \mathrm{Rh}, \mathrm{Ru}$ or Pt supported on $\gamma-\mathrm{Al}_{2} \mathrm{O}_{3}$. All the catalysts were activated at $473 \mathrm{~K}$ for $2 \mathrm{~h}$ under flowing hydrogen. Different studies confirm that these metals are completely active after this pretreatment (the position of the metal on the surface favors the $\mathrm{C}=\mathrm{O}$ hydrogenation), whereas higher reduction temperatures 
promote active phase sintering and the formation of different structures on the surface catalytically active for other side reactions[30].

Morphological properties were determined in previous works by using the nitrogen physisorption at $77 \mathrm{~K}$ in a Micromeritics ASAP 2020 analyzer by the BET method for the specific surface area and the BJH approach to determine the pore volume and diameter[31,32]. The metal particle morphology and size distribution were identified by TEM using a JEOL-2000 EX-II microscope. The strength and distribution of the acid sites were determined by temperature programmed desorption (TPD) of pre-adsorbed $\mathrm{NH}_{3}$ in a MicromeriticsTPD/TPR 2900. Samples (10 mg) were treated in $\mathrm{He}$ at $623 \mathrm{~K}$ for $2 \mathrm{~h}$ and exposed to a $2.5 \% \mathrm{NH}_{3}$ in $\mathrm{He}$ stream at $323 \mathrm{~K}$ until saturation. After the stabilization, the temperature was increased at a rate of $5 \mathrm{~K} / \mathrm{min}$ and the $\mathrm{NH}_{3}$ evolution was monitored by mass spectrometry. Further details about the acidity measurements are given in previous works[33].

\subsection{Reaction studies}

Reactions were carried out in a $0.5 \mathrm{~L}$ stirred batch autoclave reactor (Autoclave Engineers EZE Seal) equipped with a PID temperature controller and a back pressure regulator. The reactor was loaded with $0.25 \mathrm{~L}$ of a hexane solution of $0.42 \mathrm{~g}$ of furfuryldeneacetone (Alfa Aesar, $98 \%$ ). The catalyst $(60 \mathrm{mg})$, with an average particle diameter of $50-80 \mu \mathrm{m}$, was added and air is purged out by adding nitrogen up to $1.5 \mathrm{MPa}$ for three times before starting the reaction. The concentration of $\mathrm{C} 8$, as well as the catalyst/reactant ratio was chosen considering the $\mathrm{C} 8$ maximum concentration obtained in previous works related to the furfural-acetone aldolcondensation[4]. Selected reactant concentration also ensures that the solubility of the reactants or reaction products does not affect catalytic performance. 
The reactor was initially pressurized to $2.5 \mathrm{MPa}$ with $\mathrm{H}_{2}$, heated to reaction temperature (reaching final pressures of $5.5 \mathrm{MPa}$ ) and stirred at $1000 \mathrm{rpm}$ for $8 \mathrm{~h}$ for the screening of the different metals (reactions at $393 \mathrm{~K}$ ) or $24 \mathrm{~h}$ in the studies of the influence of the temperature (393, 433, 453 and $493 \mathrm{~K}$ ). Selected pressure guarantees the $\mathrm{H}_{2}$ excess during all the experiment, since the amount of hydrogen needed for the total hydrogenation of the adduct was less than a 10 $\%$ of the total amount of hydrogen loaded in the reactor. This fact was also experimentally checked both experimentally, the pressure after $24 \mathrm{~h}$ only decreases in 0.3-0.5 $\mathrm{MPa}$ when hydrogen is not fed; and theoretically, assuming the Henry's equilibrium for the hydrogenhexane system.

Samples were withdrawn from the sampling port during the reaction, filtered and analyzed by capillary GC in a Shimadzu GC-2010 equipped with a FID detector, with a CP-Sil5 capillary column as stationary phase. Peak assignment was performed by GC-MS and responses were determined using standard calibration mixtures and the effective carbon number concept[34]. The structure of the different isomers can be observed in Scheme 2. Due to the complexity of their nomenclature, each compound was labeled with a capital letter that will be used during the discussion.

The stability of the catalysts was tested by repeating the batch experiments with recovered catalysts. The maximum decrease in conversion observed was $10 \%$, whereas the selectivities of total hydrogenated products showed just slight decreases $(<5 \%)$. Therefore, catalyst deactivation has not being considered in further discussions. Characterization of the used catalysts (nitrogen physisorption, XRD) does not reveal any morphological or crystallographic change during the reaction. 


\section{Results and discussion}

\subsection{Catalytic activity}

Batch experiments at $393 \mathrm{~K}$ and $4.5 \mathrm{MPa}$ were performed with the selected catalysts in order to identify the most active metal and determine the reaction pathways for the hydrogenation of the studied condensation adduct. This temperature was chosen considering previous works about the hydrogenation of other biomass-derived compounds[23]. The reaction time was in all cases 8 hours. The most active catalyst was identified considering both the selectivity of n-octane (labeled as "E") and the carbon balance. The selectivity was calculated as the ratio between the concentration of n-octane and the concentration of converted $\mathrm{C} 8$-condensation adduct.

Reaction profiles obtained with the four catalysts are given in the Figure 1. These profiles are characterized by a fast disappearance of the reactant with total reactant conversion after less than 4 hours (best results for $\mathrm{Pt} / \mathrm{Al}_{2} \mathrm{O}_{3}$, with total conversion after 2 hours). This drop in the reactant concentration is directly related to the appearance of the first intermediate (labeled as "B"), characterized by the selective hydrogenation of the aliphatic $\mathrm{C}-\mathrm{C}$ double bond. In the case of $\mathrm{Ru}$ and Rh supported catalysts, the profile of the B intermediate reaches a maximum (selectivities of $80-85 \%)$ and the concentration remains in values close to the maximum. On the other hand, when Pd or Pt/alumina are used as catalysts, the maximum of this intermediate is reached faster (less than 2 hours) and its concentration dropsto values close to zero at the end of the experiments. This decrease is more sharply for Pt/aluminadue to the hydrogenation of more stable insaturations (cyclic-aromatic bonds, carbonyl groups) to obtain other intermediates 
(labeled as "C" and "D") and the n-alkane ("E"). The most unstable intermediate is the opencycle "D", whose selectivity never reached values higher than $3 \%$, although a maximum is clearly observed. Previous results confirmed that Pd is very selective for hydrogenation aliphatic unsaturated aldehydes[30], but $\mathrm{Pt}$ is much more active in deoxygenation reactions [29].Consequently, the selectivity of n-octane obtained with Pt/alumina (9.4\%) was higher than forPd/alumina (6.1\%). The carbon balance closures obtained were, in all the cases, higher than $95 \%$, discarding the presence of other side reactions such asdecarbonylationsor the formation of heavy adsorbed by-products.

The modest n-octane selectivities obtained in both cases (with $\mathrm{Pd}$ and $\mathrm{Pt}$ ) is due to the reaction parameters: the short reaction time (profiles suggest increasing trends for n-octane selectivity at longer times) or the reaction temperature. In fact, the complete hydrodeoxygenation of polyfunctionalized molecules was carried out at higher temperatures (over650 K) to guarantee the complete reaction, with negligible activity at temperatures lower than 400K[7]. The evolution of the activity at higher temperatures $(433,453$ and $493 \mathrm{~K})$ was tested with the most active catalysts ( $\mathrm{Pd}$ and $\mathrm{Pt} /$ alumina).Figure 2 comparesselectivities after 24 hours of reaction. In both cases, the n-octane selectivity increaseswith the temperature, reaching values of 25 and $35 \%$ with Pd and Pt, respectively. However, the differences between both materials are more noticeable analyzing the distribution of the different reaction intermediates. The first intermediate ("B") reaches almost $40 \%$ of the final selectivity (at low and medium temperatures) on the Pd/alumina catalysts, whereas lower than $25 \%$ on Pt/alumina. The high selectivity of Pd for aliphatic unsaturated hydrogenations in contrast with the low activity in presence of cyclic compounds was previously observed in hydrogenations of compounds as benzaldehyde or acetophenone[30]. 
Concerning to the carbon balances, in both cases, decrease with the temperature. This behavior is more noticeable with $\mathrm{Pd} /$ alumina (from $97.7 \%$ at $393 \mathrm{~K}$ to $63.7 \%$ at $493 \mathrm{~K}$ ), whereas for Pt/alumina the variation was lower than $10 \%$ (from $98.1 \%$ at $393 \mathrm{~K}$ to $88.8 \%$ at $493 \mathrm{~K}$ ).At first insight, this carbon unbalance can be caused by side reactions leading to condensation products, such as Diels-Alder reactions. At this point, the larger selectivities observed for the intermediate "B" with two conjugated C-C double bonds (active for Diels-Alder reactions) can be the responsible of these differences.

\subsection{Kinetic study}

The evolution of the selectivity of different products as function of the C8-condensated conversion is plotted in Figure 3 for all the catalysts at 393 K. The compound labeled as "B" shows a typical profile of primary reaction product undergoing further reactions.By contrast, " $\mathrm{C}$ " intermediate follows the typical pattern of a secondary product, being its selectivity negligible at zero conversion and reaching a maximum for $\mathrm{Pd}$ and $\mathrm{Pt} /$ alumina catalysts and a plateau for $\mathrm{Ru}$ and $\mathrm{Rh}$ /alumina. For the case of $\mathrm{Pd}$, significant selectivity for " $\mathrm{C}$ " is observed at zero conversion, suggesting its direct formation from the reactant. The evolution of the " $\mathrm{C}$ " intermediate at high conversionssuggests that $\mathrm{Ru}$ and $\mathrm{Rh} /$ alumina are active for the hydrogenation of the aliphatic $\mathrm{C}$ C bond, but not for the $\mathrm{C}-\mathrm{O}$ bond hydrogenolysis. It should be notedthat these catalysts did not show activity neither for hydrodeoxygenation nor forother polymerization reactions that had been reported in similar reactions carried outusing $\mathrm{Ru}$ as active metal [35]. However, the experiments reported in this work have been performedat higher pressures and using largely higher catalyst/reactant ratios [35]. 
Concerning to the reaction scheme, results clearly indicate that the hydrogenation of the $\mathrm{C}=\mathrm{Cbond}$ takes place as a primary reaction in all the cases, yielding the molecule " $\mathrm{B}$ ". In the case of product " $\mathrm{C}$ " (simultaneous hydrogenation of the $\mathrm{C}=\mathrm{C}$ double bond and hydrogenation of the furanic ring), the trends are not so clear. For Pd/supported catalyst, at low temperatures, the "C" compound appears at zero conversion (primary product), whereas at higher temperatures " $\mathrm{C}$ " is a secondary product, formed by hydrogenation of the furanic ring of the intermediate " $\mathrm{B}$ ". Although there are not reported studies on this specific reaction, works on the hydrogenation of conjugated systems suggest the possibility of simultaneous hydrogenation of multiple conjugated carbon-carbon double bonds. Loffreda et al. described the formation of butane as primary product in the hydrogenation of butadiene on Pt surfaces, justifying these findings on DFT studies[36].

Once " $\mathrm{B}$ " and " $\mathrm{C}$ " intermediates are formed, the next step is the ring opening, and the hydrogenation of the $\mathrm{C}=\mathrm{O}$ bond. In all cases, the presence of furanic alcohols (resulting from a single hydrogenation of the $\mathrm{C}=\mathrm{O}$ bond) and hydroxyl-carbonyl compounds (resulting from the ring opening) is discarded. Only the "D"intermediate, formed by thering opening,yielding a terminal hydroxyl group, and $\mathrm{C}=\mathrm{O}$ bond hydrogenation, has been detected. Since both functionalities are far enough for discarding a concerted mechanism, the abovementioned nonobserved intermediates are unstable and undergo fast reactions yielding the intermediate " $\mathrm{D}$ ". The high reactivity of the linear oxygenated intermediates is also supported by the low selectivities found for "D" intermediate, with maximum values always lower than $10 \%$.

To the best of our knowledge, there are not systematic studies comparing the rates of both kinds of reactions (ring opening, and $\mathrm{C}=\mathrm{O}$ bond hydrogenation), although it is suggested that both of them are slower that the hydrogenation of $\mathrm{C}=\mathrm{C}$ bonds[37]. Concerning to the precursor of " $\mathrm{D}$ " 
intermediate, at first insight, ring opening product can derive either from "B", "C" or both of them. However, Sitthisa and Resasco studied the ring-opening reaction of furan over Ni and Pd catalysts[38]. They observed, using both furan and tetrahydrofuranas reactants, that the ring opening rates are larger with the unsaturated ring. Thus, the strongest interaction of the aromatic ring with the metal, weakening the C-O bond, plays a key role in the ring opening reaction[39]. Once the intermediate " $\mathrm{D}$ " is formed, it undergoes fast dehydration-hydrogenation steps yielding octane.

According to this mechanism, it is predicted that the intermediate "C" shows the behavior of a non-reactive secondary product, not undergoing further reaction. Although this is the most common pattern, there are cases (especially with $\mathrm{Rh}$ and Pt catalysts) in which the selectivity for the formation of this compound shows a slight decrease at higher conversions. This behavior is explained considering that the hydrogenation of the furanic ring can be partially reversible. Equilibrium in the hydrogenation of aromatic cycles was previously observed for the hydrogenation of polyaromatic compounds[40].

Other side reactionsare discarded due to the high carbon balance closures and the chemical analysis of the reaction mixture.GC-MS identification analyses were carried out, detecting only compounds with eight carbon atoms. Consequently, polymerization andhydrocycloaddition reactions were discarded at our reaction conditions. Interestingly, neither reaction products resulting from $\mathrm{C}-\mathrm{C}$ bond cleavage were found. By contrast, during the hydrodeoxygenation of furfural over supported noble metals, important amounts of decarbonylation products (furan and $\mathrm{CO}$ ) were found, specially using Pd as catalyst[41]. It is remarkable that the carbonylic carbon atom is more electropositive in the furfural molecule than in the intermediate " $\mathrm{B}$ ", where the terminal methyl group and the intermediate carbon chain decrease the electropositive character 
of this carbon atom (inductive effect). Taking into account all these facts, a kinetic model as the depicted in Scheme 3 is proposed for modeling the reaction.

The temporal evolution of the concentration of reactant, reaction intermediates and the n-octane with reaction time wasmodeled using the SCIENTIST ${ }^{\circledR}$ software, applying the Burlich-Stoer approximation in order to determine the kinetic constants for each step.Each elementary step has been considered to follow a pseudo-first order kinetics on the organic reactant. The presence of different organic reactants with similar molecular structure prevents the use of more mechanistic models, such as Langmuir-Hinshelwood ones. The presence of mass transfer effect has been discarded by ensuring the small catalytic particle size and with the high stirring, so this reaction is considered to be kinetically controlled. The high pressure (4.5 MPa)ensures that the hydrogen is in enough excess to consider zeroth order kinetic dependence.In any case, the negligible decrease in the pressure during the reaction leads us to neglect the effect of hydrogen pressure on the reaction kinetics at the studied interval.First-order kinetic dependence on the organic molecule has been considered for each step, which is in good agreement with most of the kinetic studies of liquid-phase hydrogenations[40,42]. Therefore, and considering batch reactor and the reaction scheme suggested in the analysis of the conversion-selectivity plots, the following set of differential equations are used for modeling the reaction:

$$
\begin{array}{ll}
\frac{d A}{d t}=-k_{1} \cdot A-k_{2} \cdot A & \text { Eq: I.1 } \\
\frac{d B}{d t}=k_{1} \cdot A-k_{3} \cdot B-k_{4} \cdot B+k_{-4} \cdot C & \text { Eq: I.2 } \\
\frac{d C}{d t}=k_{2} \cdot A+k_{4} \cdot B-k_{-4} \cdot C & \text { Eq: I.3 }
\end{array}
$$




$$
\begin{aligned}
& \frac{d D}{d t}=k_{3} \cdot B-k_{5} \cdot D \\
& \frac{d E}{d t}=k_{5} \cdot D
\end{aligned}
$$

Different variations of these models were also tested, increasing the number of reactions considered as reversible, or including a direct transformation of intermediate " $\mathrm{C}$ " into intermediate "D". In all the cases, fitting results were worse than in the proposed model. Thus, this kinetic model has been used for comparing the results obtained with the different catalysts.Likewise, the kinetic values were normalized considering the dispersion of the active phase according to the following expression and considering the characterization results summarized in Table 1.

$$
k^{\prime}\left(L s^{-1} \cdot a t-g_{\text {metal }}^{-1}\right)=\frac{k\left(s^{-1}\right) \cdot V(L)}{M_{c a t}(g) \cdot(\% \text { metal } / 100) \cdot\left(1 / A_{\text {metal }}\right) \cdot d}
$$

Where " $\mathrm{k}$ " is the first-order kinetic constant for a reaction rate expressed as mol reacted/formed per second and volume of feed;" $k$ "' is the first-order kinetic constant for a reaction rate expressed as mol reacted/formed per second and exposed atom of metal;" $\mathrm{M}_{\mathrm{cat}}$ " is the mass of catalyst used

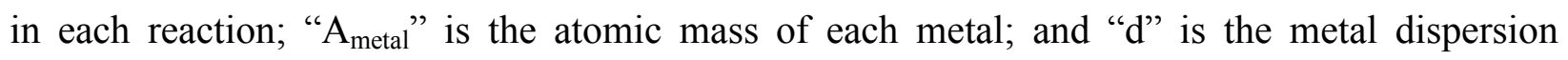
determined by TEM.

Considering the kinetic constants normalized by exposed atom of metal, possible effects of the different effective metal loading were discarded. In any case, micrographs obtained by TEM demonstrate a high similarity in terms of particle size among the four materials, with a narrow distribution around the average value, as it can be observed in Figure 4. Sincealso morphology of the catalysts and acid properties are very similar for the four studied catalysts, differences in 
catalytic performance are caused by the activity of the metal. Values of the kinetic constants for the experiments performed at 393K are reported in Table 2. The proposed model (considering the above-mentioned peculiarities for each catalyst) provides agood fit for all the experiments performed (with a correlation coefficient higher than 0.97 for all the compounds in all the reactions). The goodness of these fits is also observed in the Fig. 1 for the experiments performed at $393 \mathrm{~K}$ with the four catalysts.

According to the proposed mechanism, Pd and Pt catalystspresent similar activity for the first step of the hydrodeoxygenation (aliphatic $\mathrm{C}=\mathrm{C}$ bond hydrogenation), with the highest values of $\mathrm{k}_{1}$. This result is in good agreement with the well-known high activity and selectivity of these metals in $\mathrm{C}=\mathrm{C}$ aliphatic hydrogenations[37]. In the case of $\mathrm{Rh}$ and $\mathrm{Ru}$ catalysts, the activity is lower. These facts are in a good agreement with the trends reported for olefins hydrogenation, $\mathrm{Pt}$ and $\mathrm{Pd}$ being considered the most active catalysts for this reaction, whereas the $\mathrm{Rh}$ and $\mathrm{Ru}$ are markedly less active. Concerning to the simultaneous hydrogenation of the double bond and the furanic ring, this reaction only takes place with the Pd catalyst and at very low reaction rates (kinetic constant is ca. one order of magnitude lower than $\mathrm{k}_{1}$ ). In the other cases, the intermediate "C" is only formed by hydrogenation of the intermediate " $\mathrm{B}$ ". In this case, the supposition of a reversible step for this transformation is supported by the values of the same order of magnitude obtained for the constants $\mathrm{k}_{4}$ and $\mathrm{k}_{-4}$. The high values of the second kinetic constant for $\mathrm{Ru}$ and $\mathrm{Rh}$ catalysts explain the slight decrease in the concentration of this intermediate, which does not undergo further transformations.At this point, the behaviour of Pd differs from the other metals, being observed that the formation of intermediate "C" is irreversible.

The ring-opening reactions only take place at relevant extent with Pd and Pt catalysts $\left(\mathrm{k}_{3}\right), \mathrm{Pt}$ being the most active catalyst, whereas Pd seems to be more active for the final dehydration- 
hydrogenation step $\left(\mathrm{k}_{5}\right.$.). Comparing both steps, the first one is slower, in good agreement with the profile observed for the aliphatic diol "D". It should be noted that catalyst acidity can play a key role in the dehydration-hydrogenation step, being the acid site distribution shifted to higher concentration and strength of the acid sites for the Pd catalyst.

The different behaviour of the catalysts cannot be explained by the morphology or metal dispersion of these materials (Table 1) and, consequently, the activity can be attributed to the different affinity between the metal crystallites and the reactant and intermediate products. Some researches indicated that the activity in similar processes is conditioned by the interaction of unsaturated functional groups and hydrogen with the metal and the subsequent ability of the metal to eliminate the hydrogen atom[43]. The most stable interactions presented in $\mathrm{Pd}$ and $\mathrm{Pt}$ are $\pi$-allyl modes, and in the case ofPd this interaction is so strong that difficults desorption of the first intermediate ("B"). On the other hand, the hydrogenation of the aldehyde group is not favoured with $\mathrm{Ru}$ and $\mathrm{Rh}$ due to their low preference of these metallic surface for $\mathrm{C}=\mathrm{O}$. This affinity is important in order to stabilize the hydrogenation intermediates in molecules with ketonic groups and it is higher in the case of Pd or Pt[44].

Kinetic values obtained by fitting the experiments catalyzed by Pd and Pt catalysts at higher temperatures $(433,453$ and $493 \mathrm{~K})$ are in good agreement with the similar behaviors obtained with both catalysts at low temperatures.Kinetic constants obtained using the proposed model, at different temperatures, were used for estimating the values of the pre-exponential factor and the activation energy of each step of this reaction considering an Arrhenius model. Values obtained are summarized in Table 3. Straight lines obtained are plotted in Figure 5, observing a good linear trend. The goodnessof the proposed model is also observed in Figure 6, with a correlation coefficient higher than 0.97 for all the compounds in all the reactions.In general terms, the 
kinetics constants of all the relevant steps are higher and show sharper increases with temperature with Pt, in good agreement with the higher octane selectivity observed.

Although, at first insight, the values of the activation energies seem lower than expected, similar values were recently reported for HDO.Activation energies of about $10 \mathrm{~kJ} / \mathrm{mol}$ are obtained for the propanoic acid HDO using supported Pd catalysts[45]. Concerning to biomass model compounds (furans, aldehydes, etc.), activation energy values ranging from $48 \mathrm{~kJ} / \mathrm{mol}$ of furfural hydrodeoxygenation catalyzed by $\mathrm{Cu} / \mathrm{SiO}_{2}[16]$ to $70 \mathrm{~kJ} / \mathrm{mol}$ of phenol $\mathrm{HDO}$ catalyzed by $\mathrm{Pd} / \mathrm{C}[46]$ were reported.Kinetic studies of individual steps in hydrodeoxygenation processes catalyzed by noble metals using different solvents justified the Ea lower values obtained (from 12 to $28 \mathrm{~kJ} / \mathrm{mol}$ ) by a strong solvation of the adducts and the metal surface by the organic solvent[46].Although obtained values might suggest the presence of external or internal mass transfer limitations, both of them have been discarded by ensuring that particle size and stirring reaction do not affect obtained results, and also by theoretical considerations based on the Frössling equation and the Sherwood, Reynolds and Schmidt dimensionless numbers[47]. The calculated values for the reactant mass transfer coefficient $\left(\mathrm{k}_{\mathrm{g}}=4.7 \mathrm{~m} / \mathrm{s}\right)$ and internal diffusivity (Thiele modulus value of $\left.3.6 \cdot 10^{-6}\right)$ for the most unfavorablecase $\left(\mathrm{Pt} / \mathrm{Al}_{2} \mathrm{O}_{3}\right.$ at $493 \mathrm{~K}$ ) indicate insignificant external and intraparticle mass transfer limitations under the investigated conditions.

In general terms, the activation energies of the main route reactions $(A \rightarrow B \rightarrow D \rightarrow E)$ are very similar for both catalysts, except in the last step whose activation energy is lower for Pd. In both cases, the lowest kinetic constant and the largest activation rates were found for the ring-opening reaction, suggesting that this is the controlling step in this reaction. 


\section{CONCLUSIONS}

Four alumina-supported metals were tested in the hydrodeoxygenation of the C8-condensated adduct. $\mathrm{Ru}$ and $\mathrm{Rh} /$ alumina were discarded because of the negligible n-octane selectivity obtained after 8 hours at $393 \mathrm{~K}$. Otherwise, $\mathrm{Pd}$ and Pt/alumina showed high activity with selectivities to total hydrogenated products at $493 \mathrm{~K}$, higher than 25 and 35\%, respectively.

The activity results were used to analyze the mechanism and the catalytic properties more relevant for this reaction. The different profiles obtained with Pd and Pt catalysts were justified considering the different interaction between the insaturations and the metal surface. A kinetic model has been proposed and experimentally validated.

\section{ACKNOWLEDGMENTS}

This work was supported by the Spanish Government (contract CTQ2011-29272-C04-02). L. Faba thanks the Government of the Principality of Asturias for a Ph.D. fellowship (Severo Ochoa Program).

\section{REFERENCES}

[1]. N.R. Singh, W.N. Delgass,F.H. Ribeiro,R. Agrawal, Environ. Sci. Technol. 44(13) (2010) 5298-5305.

[2]. L. Faba, E. Díaz, S. Ordóñez, Catal. Today 164 (2011) 451-456.

[3]. T.N. Phan, D. Shi, D.E. Resasco, Appl. Catal. B 145 (2014) 10-23. 
[4]. L. Faba, E. Díaz, S. Ordóñez, Appl. Catal. B 113-114 (2012) 201-211.

[5]. M. Grile, B. Likozar, J. Levec, Appl. Catal. B 150-151 (2014) 275-287.

[6]. J. C. Serrano-Ruiz, D.J. Braden, R.M. West, J.A. Dumesic, Appl. Catal. B 100 (2010) 184-189.

[7]. A. Popov, E. Kondratieva, J.M. Goupil, L. Mariey, P. Bazin, J.P. Gilson, A. Travert, F. Mauge, J. Phys. Chem. C 114 (2010) 15661-15670.

[8]. I. Graça, J.M. Lopes,H.S. Cerqueira, M.F. Ribeiro, Ind. Eng. Chem. Res. 52 (2013) 275287.

[9]. J. Lee, J. Xu, G.W. Huber, Appl. Catal. B 140-141 (2013) 98-107.

[10]. R.S. Rao, R.T.K. Baker, M.A. Vannice, Catal. Lett. 60 (1999) 51-57.

[11]. S. Sitthisa, W. An, D.E. Resasco, J. Catal. 284 (2011) 90-101.

[12]. L. Baijun, L. Lianhai, W. Bingchun, C. Tianxi, K. Iwatani, Appl. Catal. A 171 (1998) 117-122.

[13]. B.J. Liaw, S.J. Chiang, S.W. Chen, Y.Z. Chen, Appl. Catal. A 346 (2008) 179-188.

[14]. A.F. Shojaei, M.A. Rezvani, M.H. Loghmani, Fuel Process. Technol. 116 (2013) 161170.

[15]. D.C. Elliott, Energy Fuels 21(3) (2007) 1792-1815.

[16]. S. Sitthisa, T. Sooknoi, Y. Ma, P.B. Balbuena, D.E. Resasco, J. Catal.277 (2011) 1-13.

[17]. E.Kusema, L. Faba, N. Kumar, P. Mäki-Arvela, E. Díaz, S. Ordóñez, T. Salmi, D.Yu. Murzin, Catal. Today 196 (2012) 26-33.

[18]. J.M. Medlin, ACS Catal.1 (2011) 1284-1297.

[19]. E. Furimsky, Catal. Rev-Sci. Eng. 25 (1983) 421-458.

[20]. R.M. West, Z.Y. Liu, M. Peter, J.A. Dumesic, ChemSusChem1 (2008) 417-424. 
[21]. M. Chatterjee, K. Matsushima, Y. Ilushima, M. Sato, T. Yokoyama, H. Kawanami, T. Suzuki, Green Chem. 12 (2010) 779-782.

[22]. P.M. Mortensen, J.D. Grunwaldt, P.A. Jensen, A.D. Jensen, ACS Catal. 3 (2013) 1774-1785.

[23]. C.H. Barret, J.N. Chheda, G.W. Huber, J.A. Dumesic, Appl. Catal. B 66 (2006) 111-118.

[24]. J.N. Chheda, J.A. Dumesic, Catal. Today 123 (2007) 59-70.

[25]. A. Vargas, S. Reimann, S. Diez, T. Mallat, A. Baker,J. Mol. Catal. 282 (2008) 1-8.

[26]. J. Panpranot, K. Pattamakomsan, J.G. Goodwin, P. Praserthdam, Catal. Commun. 5 (2004) 583-590.

[27]. K. Scott, N. Basov, R.J.J. Jachuck, N. Winterton, A. Cooper, C. Davies, Chem. Eng. Res. Des. 83 (2005) 1179-1185.

[28]. B. Bachiller-Baeza, A. Guerrero-Ruiz, I. Rodríguez-Ramos, Appl. Catal. A 192 (2000) 289-297.

[29]. D. Procházková, P. Zámostný, M. Bejblová, L. Cervený, J. Cejka, Appl. Catal. A 132 (2007) 56-64.

[30]. P. Mäki-Arvela, J. Hájek, T. Salmi, D.Yu. Murzin, Appl. Catal. A 292 (2005) 1-49.

[31]. E. Díaz, S. Ordóñez, A. Vega, J. Coca, MicroporousMesoporous Mater. 70 (2004) 109-118.

[32]. E. Díaz, S. Ordóñez, A. Vega, J. Coca, MicroporousMesoporous Mater. 77 (2005) 245255.

[33]. F. Arena, R. Dario, A. Parmaliana, Appl. Catal. A 170 (1998) 127-137.

[34]. J.T. Scanlon, D.E. Willis, J. Chromatogr. Sci. 23(8) (1985) 333-340.

[35]. H. Olcay, A.V. Subrahmanyam, R. Xing, J. Lajoie, J.A. Dumesic, G.W. Huber, EnergyEnviron. Sci. 6 (2013) 205-216 
[36]. D. Loffreda, C. Michel, P. Delbecq, P.Sautet, J. Catal. 368 (2013) 374-385

[37]. R. Zanella, C. Louis, S. Giorgio, R. Touroude,J. Catal. 223 (2004) 328-339.

[38]. S. Sitthisa, D.E. Resasco, Catal. Lett.141 (2011) 784-791

[39]. M.K. Bradley, J. binRoson, D.P. Woodruff, Surf. Sci. 604 (2010) 920-925.

[40]. M.J. Girgis, B.C. Gates, Ind. Eng. Chem. Res. 30 (1991) 2021-2058.

[41]. J. Yang, N. Li, G. Li, W. Wang, A. Wang, X. Wang, Y. Cong, T. Zhang, ChemSusChem 6(2013) 1149-1152.

[42]. E. Furimsky, Catal. Today 217 (2013) 13-56.

[43]. I.V. Deley, I.L. Simakova, N. Rovasio, R. Psaro, Appl. Catal. A 257 (2009) 170-177.

[44]. P. Panagiotopoulou, D.I. Kondarides, X.E. Verykios, Appl. Catal. A 344 (2008) 45-54.

[45]. Y.K. Lugo-Jose,J.R. Monnier, C.T. Williams, Appl. Catal. A 469 (2014) 410-418.

[46]. J. He, C. Zhao, J.A. Lercher, J. Catal. 309 (2014) 362-375.

[47]. H.S. Fogler, M.N. Gürmen, Elements of Chemical Reaction Engineering, 2008, ed. Pearson, 4 Ed, ch. 11. 


\section{SCHEME CAPTIONS}

Scheme 1: General mechanism for biodiesel synthesis from hemicellulosic biomass by dehydration-aldolization-hydrogenation/deoxygenation.

Scheme 2: Chemical structure of the reactant (A) and reaction products identified by GC-MS during the hydrodeoxygenation of furfuryldeneacetone.

Scheme 3: Reaction mechanism proposed to the hydrodeoxygenation of the furfuryldeneacetone.

\section{TABLE CAPTIONS}

Table 1: Summary of the main morphological and chemical properties (TEM, $\mathrm{N}_{2}$ physisorption and TPD-NH 3 ) of the catalysts used in this work

Table 2: Kinetic constants $\left(\mathrm{L} \cdot \mathrm{s}^{-1} \cdot\right.$ at- $\left.\mathrm{g}_{\text {cat exp }}\right)$ for the fitting of the experimental results at $393 \mathrm{~K}$ to the proposed kinetic model.

Table 3: Activation energy and pre-exponential value obtained by Arrhenius model

\section{FIGURE CAPTIONS}

Figure 1: Concentration profiles obtained in HDO of C8-condensated at 393 K.Symbols:(•) "A"; ( घ ) “B”; ( ) “C”; ( $\triangle$ ) “D”; $(\triangleright)$ “E” (see Scheme 2 for notation).

Figure 2: Final selectivities obtained after 24 hours of reaction at different temperatures using $\mathrm{Pd} / \mathrm{Al}_{2} \mathrm{O}_{3}$ or $\mathrm{Pt} / \mathrm{Al}_{2} \mathrm{O}_{3}$ as catalyst. Results obtained at $95 \%$ of conversion. 
Figure 3: Evolution of the selectivity of each intermediate as function of the C8-condensated conversion in the hydrodeoxygenation with the different catalysts used in this work. (See Figure 1 for codes)

Figure 4: TEM micrographs: (a) $\mathrm{Ru} / \mathrm{Al}_{2} \mathrm{O}_{3}$, (b) $\mathrm{Rh} / \mathrm{Al}_{2} \mathrm{O}_{3}$, (c) $\mathrm{Pd} / \mathrm{Al}_{2} \mathrm{O}_{3}$ and (d) $\mathrm{Pt} / \mathrm{Al}_{2} \mathrm{O}_{3}$.

Figure 5: Arrhenius dependence of the kinetic constants (see Scheme 3) on the absolute temperature for the HDO of the condensation adduct over Pd (left) and Pt (right catalysts). Kinetic constants: $\mathrm{k}_{1}{ }_{1}(\diamond), \mathrm{k}_{2}{ }_{2}(\square), \mathrm{k}_{3}{ }_{3}(\odot), \mathrm{k}_{4}{ }_{4}(\Delta), \mathrm{k}_{5}{ }_{5}(\Delta), \mathrm{k}_{-4}(\square)$

Figure 6: Summary of the results obtained at different temperatures in terms of parity plots for the concentration of the reactant and all the reaction products. 


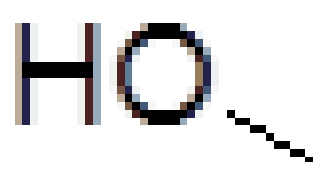

Scheme 1: General mechanism for biodiesel synthesis from hemicellulosic biomass by dehydration-aldolization-hydrogenation/deoxygenation 
Scheme 2: Chemical structure of the reactant (A) and reaction products identified by GC-MS during the hydrodeoxygenation of furfuryldeneacetone. 
B

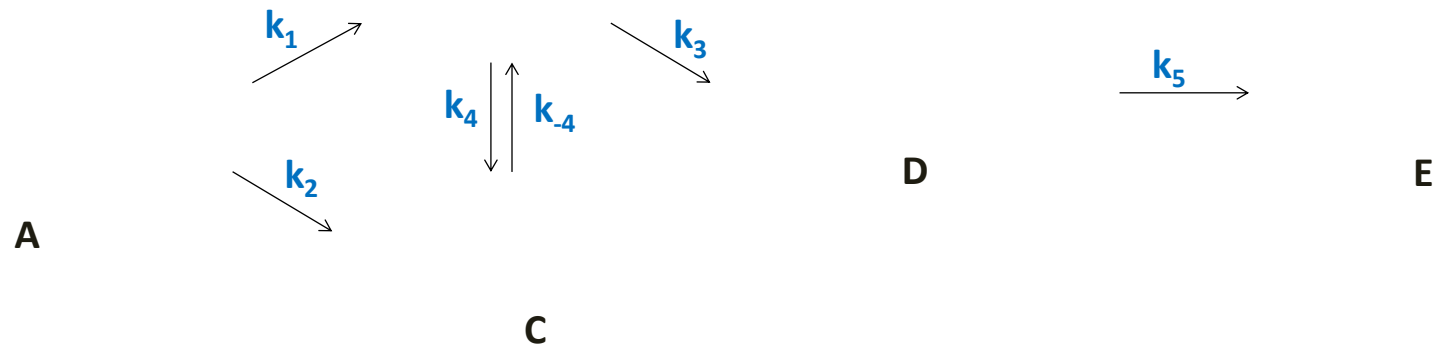

Scheme 3: Reaction mechanism proposed to the hydrodeoxygenation of the furfuryldeneacetone 


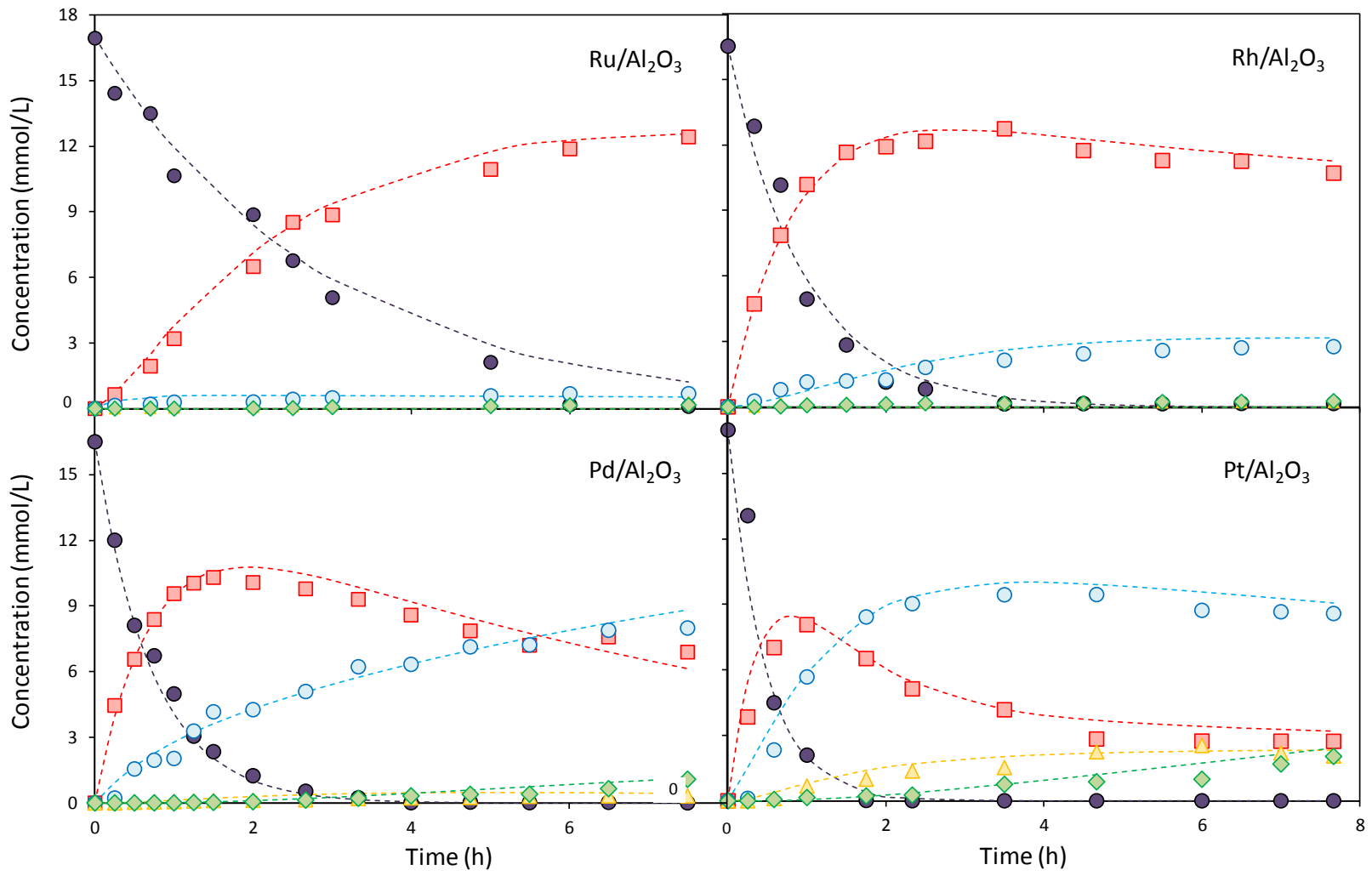

Figure 1: Concentration profiles obtained in HDO of C8-condensated at $393 \mathrm{~K}$. Symbols: (•)

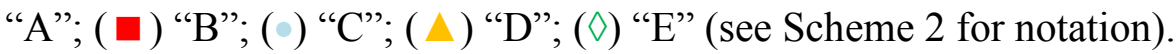




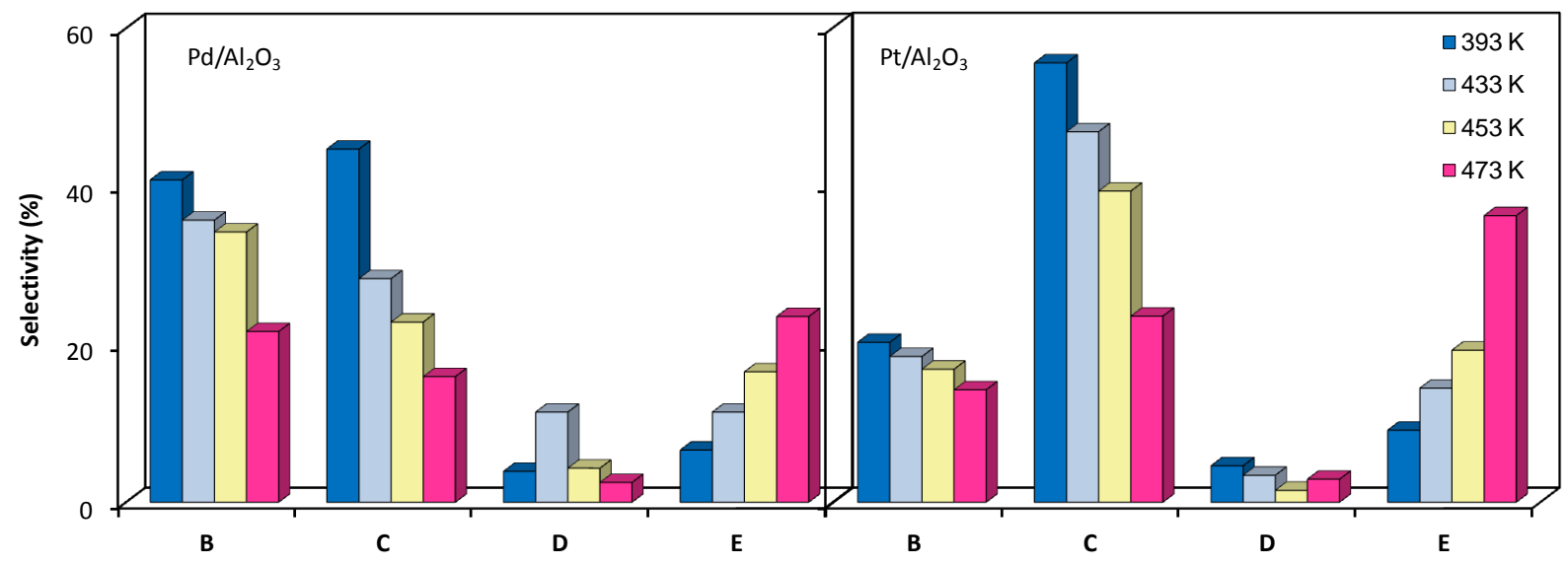

Figure 2:Selectivities obtained after 24 hours of reaction at different temperatures using $\mathrm{Pd} / \mathrm{Al}_{2} \mathrm{O}_{3}$ or $\mathrm{Pt} / \mathrm{Al}_{2} \mathrm{O}_{3}$ as catalyst. 


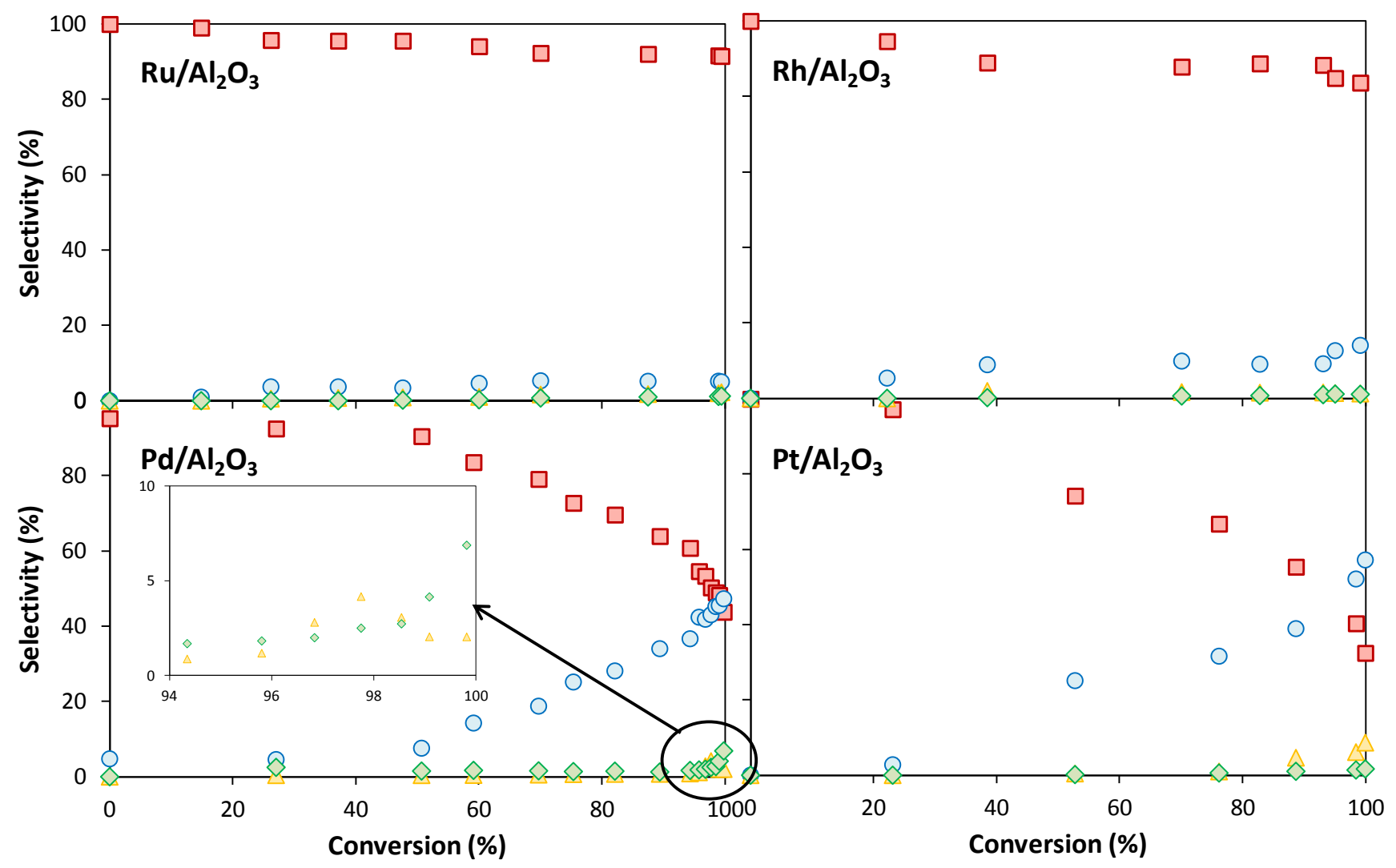

Figure 3: Evolution of the selectivity of each intermediate as function of the $\mathrm{C} 8$-condensated conversion in the hydrodeoxygenation with the different catalysts used in this work. (See Figure 1 for codes) 


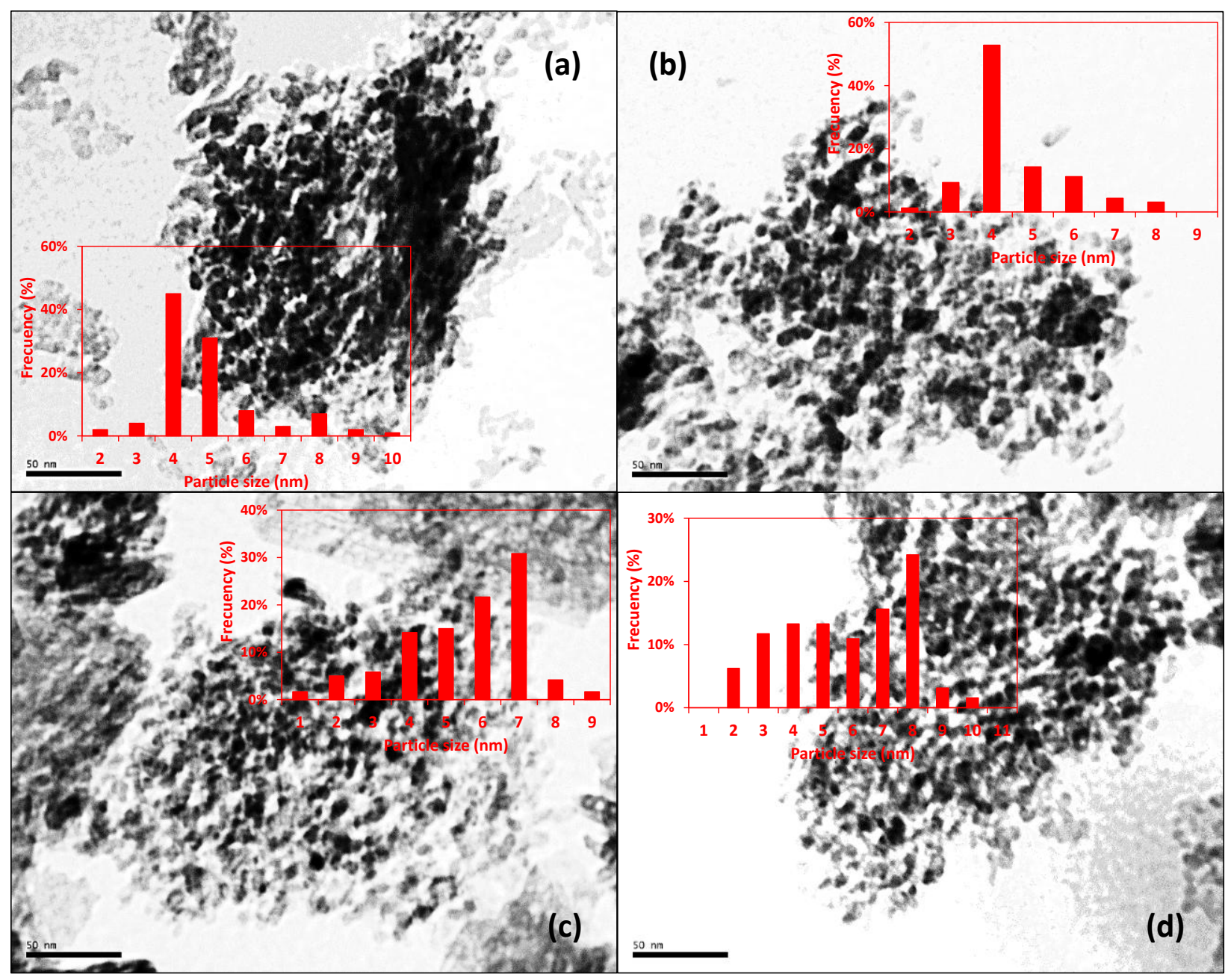

Figure 4: TEMmicrographs: (a) $\mathrm{Ru} / \mathrm{Al}_{2} \mathrm{O}_{3}$, (b) $\mathrm{Rh} / \mathrm{Al}_{2} \mathrm{O}_{3}$, (c) $\mathrm{Pd} / \mathrm{Al}_{2} \mathrm{O}_{3}$ and (d) $\mathrm{Pt} / \mathrm{Al}_{2} \mathrm{O}_{3}$. 


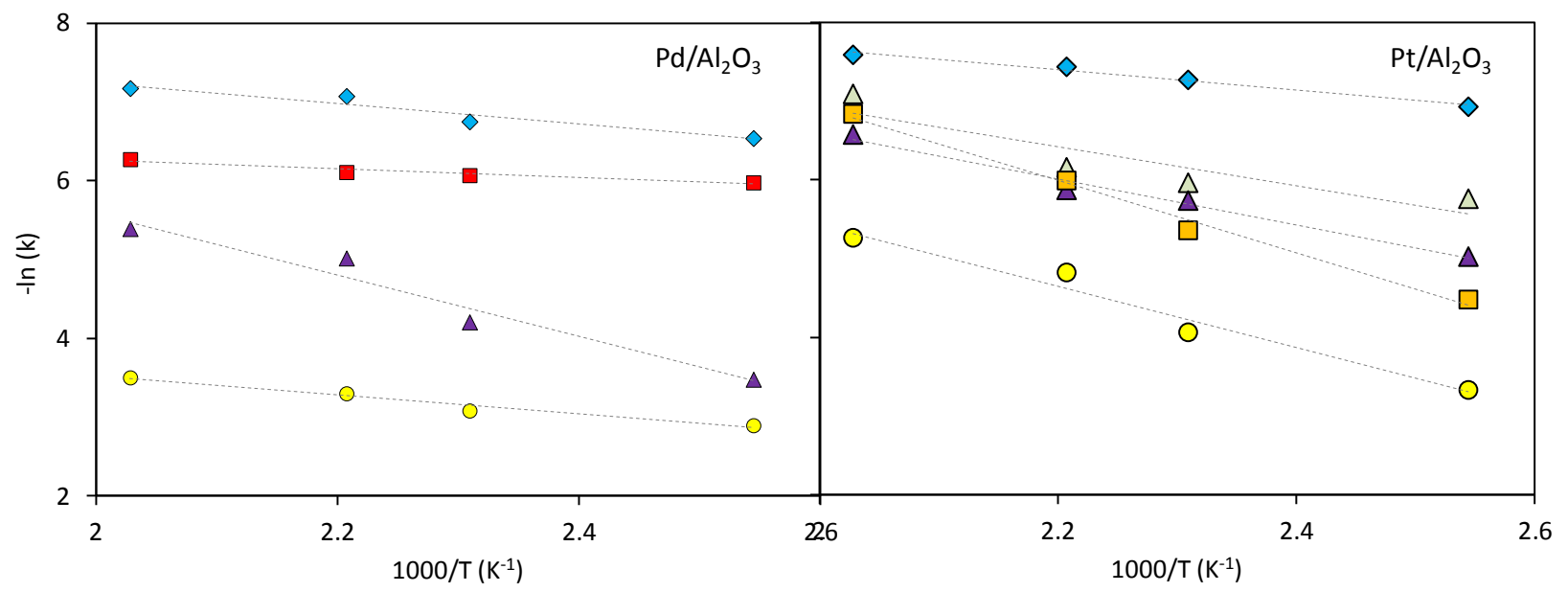

Figure 5: Arrhenius dependence of the kinetic constants (see Scheme 3) on the absolute temperature for the HDO of the condensation adduct over Pd (left) and Pt (right catalysts).

Kinetic constants: $\mathrm{k}_{1}{ }_{1}(\diamond), \mathrm{k}_{2}{ }_{2}(\square), \mathrm{k}_{3}(\odot), \mathrm{k}_{4}{ }_{4}(\Delta), \mathrm{k}_{5}{ }_{5}(\Delta), \mathrm{k}_{-4}(\square)$ 


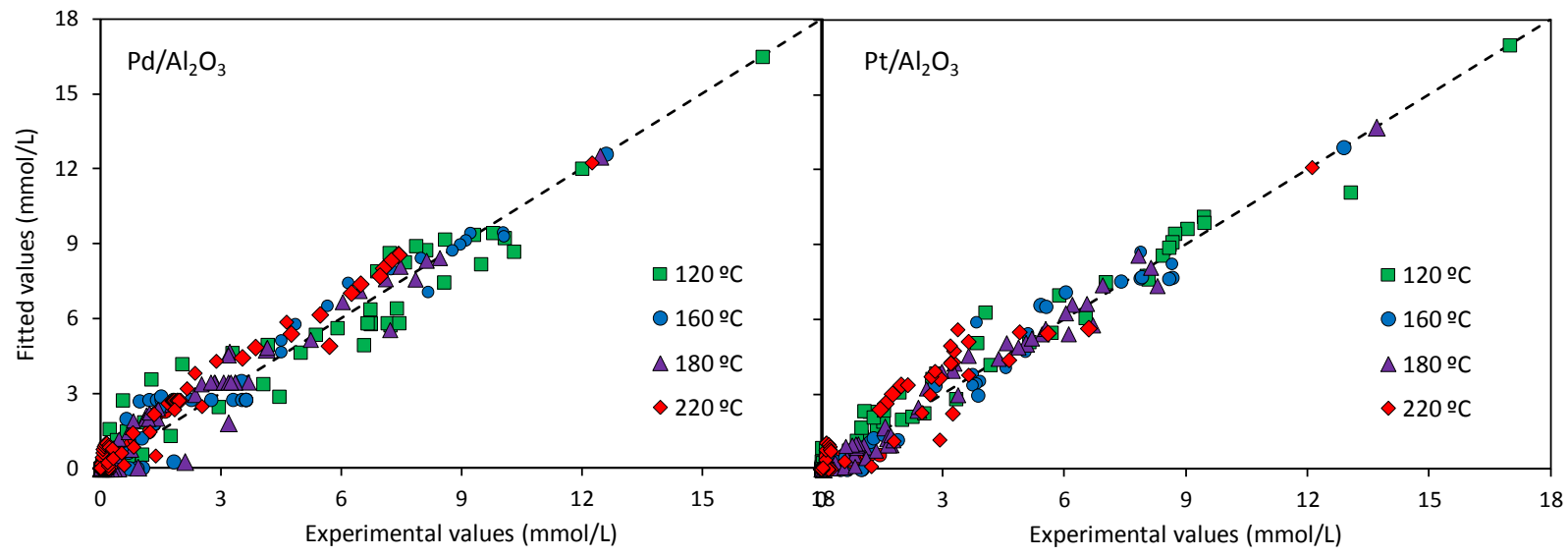

Figure 6: Summary of the results obtained at different temperatures in terms of parity plots for the concentration of the reactant and all the reaction products. 
Table 1: Summary of the main morphological and chemical properties (TEM, $\mathrm{N}_{2}$ physisorption and TPD-NH 3 ) of the catalysts used in this work

\begin{tabular}{|c|c|c|c|c|c|c|c|}
\hline \multirow[b]{2}{*}{ Catalyst } & \multicolumn{2}{|c|}{ TEM } & \multicolumn{3}{|c|}{ Morphological properties* } & \multicolumn{2}{|c|}{ Acid sites $(\mu \mathrm{mol} / \mathrm{g},(\mathrm{K}))$} \\
\hline & $\begin{array}{l}\text { Dispersion } \\
(\%)\end{array}$ & $\begin{array}{c}\text { Particle } \\
\text { size (nm) }\end{array}$ & $\begin{array}{c}\text { Specific } \\
\text { surface area } \\
\left(\mathrm{m}^{2} / \mathrm{g}\right)\end{array}$ & $\begin{array}{c}\text { Pore } \\
\text { diameter } \\
(\mathrm{nm})\end{array}$ & $\begin{array}{l}\text { Pore volume } \\
\qquad\left(\mathrm{cm}^{3} / \mathrm{g}\right)\end{array}$ & Weak & $\begin{array}{l}\text { Medium } \\
\text { strength }\end{array}$ \\
\hline $\mathrm{Ru}-\mathrm{Al}_{2} \mathrm{O}_{3}$ & 23 & 5 & 118 & 16.8 & 0.50 & $\begin{array}{l}662(409) \\
335(509)\end{array}$ & $870(642)$ \\
\hline $\mathrm{Rh}-\mathrm{Al}_{2} \mathrm{O}_{3}$ & 24 & 4 & 117 & 16.5 & 0.49 & $\begin{array}{l}895(408) \\
187(532)\end{array}$ & $702(636)$ \\
\hline $\mathrm{Pd}-\mathrm{Al}_{2} \mathrm{O}_{3}$ & 14 & 8 & 92 & 18.2 & 0.46 & $\begin{array}{l}600(337) \\
281(553)\end{array}$ & $610(685)$ \\
\hline $\mathrm{Pt}-\mathrm{Al}_{2} \mathrm{O}_{3}$ & 24 & 4 & 116 & 17.0 & 0.49 & $798(453)$ & $119(660)$ \\
\hline
\end{tabular}

* Results adapted from references Díaz et al. ${ }^{29,30}$ 
Table 2: Kinetic constants $\left(\mathrm{L} \cdot \mathrm{s}^{-1} \cdot\right.$ at- $\left.\mathrm{g}_{\text {cat exp }}\right)$ for the fitting of the experimental results at $393 \mathrm{~K}$ to the proposed kinetic model.

\begin{tabular}{c|ccccccc}
\cline { 2 - 7 } & $\mathrm{k}_{1}{ }_{1}$ & $\mathrm{k}_{2}{ }_{2}$ & $\mathrm{k}_{3}{ }_{3}$ & $\mathrm{k}^{\prime}{ }_{4}$ & $\mathrm{k}^{\prime}{ }_{5}$ & $\mathrm{k}^{\prime}{ }_{-4}$ & $\mathrm{r}^{2}$ \\
\hline $\mathrm{Pd} / \mathrm{Al}_{2} \mathrm{O}_{3}$ & $9.6 \cdot 10^{2}$ & $1.3 \cdot 10^{2}$ & $2.1 \cdot 10^{1}$ & - & $2.8 \cdot 10^{2}$ & - & 0.98 \\
$\mathrm{Pt} / \mathrm{Al}_{2} \mathrm{O}_{3}$ & $1.0 \cdot 10^{3}$ & - & $3.0 \cdot 10^{1}$ & $3.4 \cdot 10^{2}$ & $1.6 \cdot 10^{2}$ & $9.4 \cdot 10^{1}$ & 0.98 \\
$\mathrm{Rh} / \mathrm{Al}_{2} \mathrm{O}_{3}$ & $4.8 \cdot 10^{2}$ & - & - & $6.4 \cdot 10^{1}$ & - & $1.8 \cdot 10^{2}$ & 0.98 \\
$\mathrm{Ru} / \mathrm{Al}_{2} \mathrm{O}_{3}$ & $5.0 \cdot 10^{2}$ & - & - & $5.7 \cdot 10^{1}$ & - & $8.7 \cdot 10^{2}$ & 0.97 \\
\hline
\end{tabular}


Table 3: Activation energy and pre-exponential value obtained by Arrhenius model

\begin{tabular}{cccc|ccc} 
& \multicolumn{3}{c|}{$\mathrm{Pd} / \mathrm{Al}_{2} \mathrm{O}_{3}$} & \multicolumn{3}{|c}{$\mathrm{Pt} / \mathrm{Al}_{2} \mathrm{O}_{3}$} \\
\hline & $\mathrm{k}_{0, \mathrm{i}}$ & $\mathrm{Ea}(\mathrm{kJ} / \mathrm{mol})$ & $\mathrm{r}^{2}$ & $\mathrm{k}_{0, \mathrm{i}}$ & $\begin{array}{c}\mathrm{Ea} \\
(\mathrm{kJ} / \mathrm{mol})\end{array}$ & $\mathrm{r}^{2}$ \\
\hline $\mathrm{k}_{1}$ & $1.9 \cdot 10^{4}$ & 10.9 & 0.92 & $2.8 \cdot 10^{4}$ & 10.8 & 0.98 \\
$\mathrm{k}_{2}$ & $1.6 \cdot 10^{3}$ & 4.6 & 0.94 & - & - & - \\
$\mathrm{k}_{3}$ & $3.8 \cdot 10^{2}$ & 32.2 & 0.97 & $5.4 \cdot 10^{5}$ & 32.3 & 0.96 \\
$\mathrm{k}_{4}$ & - & - & - & $1.4 \cdot 10^{5}$ & 20.5 & 0.90 \\
$\mathrm{k}_{5}$ & $6.2 \cdot 10^{5}$ & 10.0 & 0.95 & $2.5 \cdot 10^{5}$ & 24.3 & 0.98 \\
$\mathrm{k}_{-4}$ & - & - & - & $1.0 \cdot 10^{7}$ & 38.3 & 0.99 \\
\hline
\end{tabular}

